\title{
EIGHT SWITCHES BRIDGE CONVERTER CHARACTERISTICS TO OPERATE THE BRUSHLESS DC MOTOR OF ELECTRIC VEHICLES
}

\author{
Mahmoud A. Hassanin, Fathy E. Abdel-Kader, Sanaa I. Amer and \\ Ahmed E. Abu-Moubarka \\ Electrical Engineering Department, Faculty of Engineering, Shebin El-Kom, \\ Minoufiya University, Egypt \\ E-mail: mhd_ahmed21@yahoo.com
}

\begin{abstract}
This paper is to investigate the performance of Brushless DC Motor (BLDCM) applied on Electric Vehicle (EV). Eight Switches Bridge Converter (ESBC) is used to drive the BLDCM to increase the system reliability. The performance characteristics of ESBC are tested at different operating conditions. The performance characteristics of ESBC are introduced by MATLAB code (m-file). An experimental setup is implemented for verifying the simulation analysis. A comparison between the theoretical and experimental results confirms the validity of the simulation.

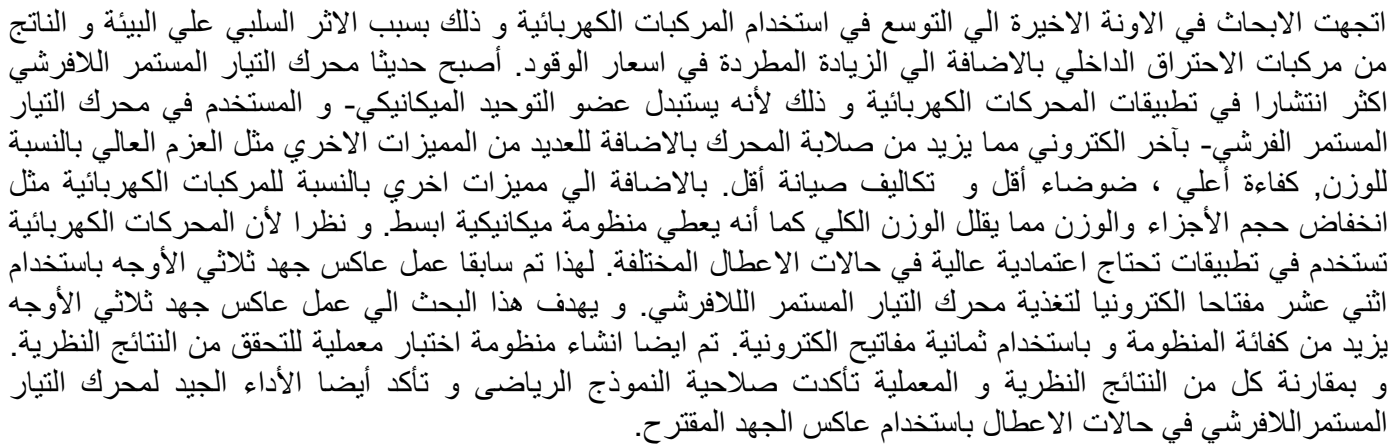

Keywords: Brushless DC Motor (BLDCM), Electric Vehicle (EV), Eight Switches Bridge Converter (ESBC), System reliability.

\section{INTRODUCTION}

Recently, the increasing concern over the environmental impact of the internal combustion engine vehicles (ICEVs), together with the soaring of oil prices, has led to a renewed interest in electric vehicles (EVs). EV will be more and more popular in the development of the world in the next decades for many reasons like saving petrol, low pollution, and high efficiency compared to ICEVs. EV uses electrical motors for propulsion, there are four major types of electrical motor drives used for EVs as follows: brushed DC Motor (BDCM) drives, induction motor drives, Switched Reluctance Motor (SRM) drives and brushless DC Motor (BLDCM) drives. Newly, BLDCM is becoming increasingly popular because it replaces mechanical commutator used in BDCM with an electronic devices that improve reliability in addition to many advantages compared with BDCM- like high torque per weight, more efficient, reduced noise and maintenance-free operation. In addition to advantages in EV hub such as: reduced hardware size and weight, simplified transmission mechanism and no reduction gear. [1-4]

\section{State of Art:}

BLDC motors are generally powered by a conventional three-phase half-bridge converter as shown in Fig. (1). $[5,11]$

The system reliability should be taken into account especially at EV applications. In a faulty case, the motor has to still operate even with lower performance in order to park the car or reach home. To improve the reliability of the system, the commonly admitted idea is to increase the redundancy. For example, increase the number of motor phases or increase the complexity of the converter. Another solution is to design the system to limit the effects of a fault. Mecrow advises to separate the phases mechanically and electrically. [7] 
Mechanical separation, realized by having one slot per winding, prevents from having inter-phase short circuit. Electrical separation allows controlling phases independently, which is possible with a full bridge three-phase converter since phases are electrically separated as shown in Fig. (2).

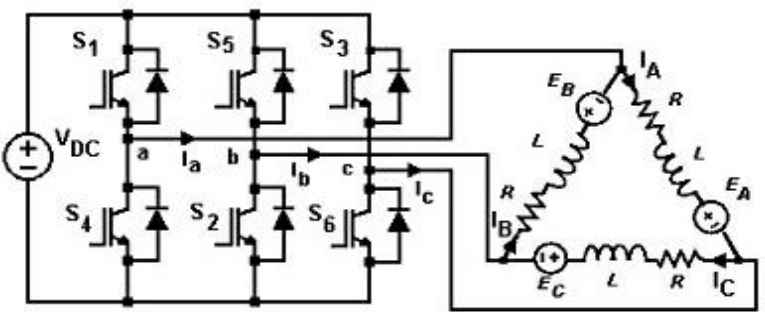

Fig. (1) Half bridge converter

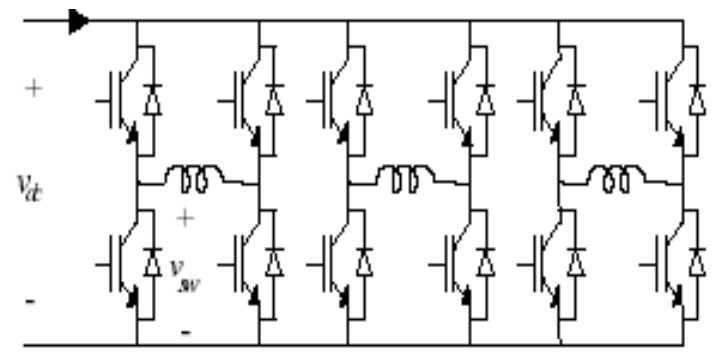

Fig. (2) Three-Phase full-bridge Converter

The three phase full bridge converter creates a redundancy by using twice as many components as a half bridge converter. Its allows disconnecting easily the faulty phase without any consequences on the remaining phases [6].

The main advantage of half bridge converter is that it needs fewer components. Besides, for half-bridge converter the motor is usually star-mounted, it is supposed that the system is balanced, in this case, the sum of the currents is null. In case of fault the system is not balanced anymore as The zero sequence component is different from zero. [6-7]

On the other hand, most of the failures are due to a dysfunction of a switching components. The weak part of the system is definitely the converter. That is why this study is focused on converter.

\section{EIGHT SWITCHES BRIDGE CONVERTER}

For cost limitations the number of switches has to be as lower as possible. So, Eight Switches Bridge Converter (ESBC) was proposed to achieve electrical separation between phases and increase reliability of the system as shown in Fig. (3).

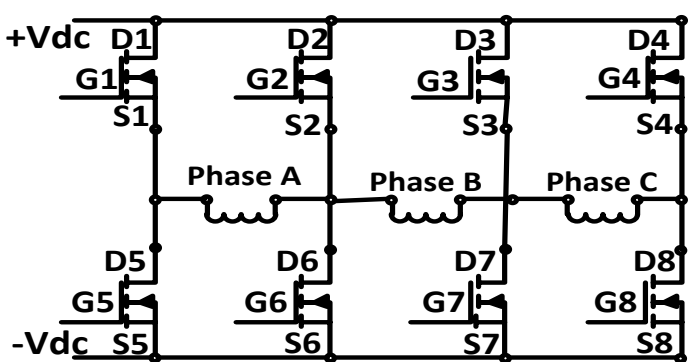

Fig. (3) Eight Switches Bridge Converter

\section{MATHEMATICAL MODELING OF BLDCM}

BLDC Motors are permanent magnet motors where the function of commutator and brushes were implemented by solid state switches. BLDC motors come in single-phase, 2-phase and 3-phase configurations. The three-phase motors are the most popular and widely used. Due to the surface permanent magnet of the motor it produces a trapezoidal back electromotive force (EMF). The motor current generates a pulsating torque. $[8,9,10]$

\section{Three-phase BLDCM equations}

$$
\begin{aligned}
& v a=i a R a+L a \frac{d i a}{d t}+M a b \frac{d i b}{d t}+M a c \frac{d i c}{d t}+e a \\
& v b=i b R b+L b \frac{d i b}{d t}+M b a \frac{d i a}{d t}+M b c \frac{d i c}{d t}+e b \\
& v c=i c R c+L c \frac{d i c}{d t}+M c b \frac{d i b}{d t}+M c a \frac{d i a}{d t}+e c
\end{aligned}
$$

Assuming three phase balanced system, so:

$R a=R b=R c=R$

And the stator self-inductances are independent of the rotor position, hence:

$L a=L b=L c=L$

Then mutual inductances will have the form:

$M a b=M a c=M b a=M b c=M c a=M c b=M$

By rearranging the above equations:

$$
\begin{aligned}
& v a=i a R+L \frac{d i a}{d t}+M \frac{d i b}{d t}+M \frac{d i c}{d t}+e a \\
& v b=i b R+L \frac{d i b}{d t}+M \frac{d i a}{d t}+M \frac{d i c}{d t}+e b \\
& v c=i c R+L \frac{d i c}{d t}+M \frac{d i b}{d t}+M \frac{d i a}{d t}+e c
\end{aligned}
$$

By neglecting mutual inductance:

$$
\begin{aligned}
& v a=i a R+L \frac{d i a}{d t}+e a \\
& v b=i b R+L \frac{d i b}{d t}+e b \\
& v c=i c R+L \frac{d i c}{d t}+e c
\end{aligned}
$$




\begin{tabular}{|c|c|c|c|c|c|c|}
\hline \multirow{2}{*}{ 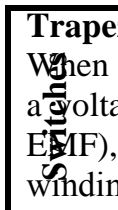 } & \multicolumn{6}{|c|}{ zoidal back-enfotor position (degree) } \\
\hline & : & ণิ: & $\begin{array}{l}\stackrel{\infty}{\infty} \\
\stackrel{\tilde{\Xi}}{\beth}\end{array}$ & 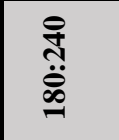 & 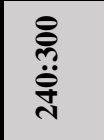 & 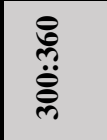 \\
\hline Q1 & $\mathbf{O N}$ & OFF & OCK-Ë & F OFFe & $\mathrm{ds} \mathrm{OF}$ & nly \\
\hline$\overline{\text { Q2 }}$ & CCOFE & ON & $\overline{\mathrm{OFF}}$ & ON & $\overline{\mathrm{OFF}}$ & $\overline{\text { OFF }}$ \\
\hline Q3 & netic fi & difer & ON & $\overline{\text { OFF }}$ & $\overline{\mathrm{ON}}$ & $\overline{\mathrm{OFF}}$ \\
\hline $\mathbf{Q 4}$ & nUFFe & ofFF & iPfFe & taßJFE & dPEF & $\mathbf{O N}$ \\
\hline$\overline{Q 5}$ & hoppot & roffe & 19OFA, & $\overline{\mathrm{ON}}$ & norgat & 100का \\
\hline Q6 & $\mathbf{O N}$ & $\mathrm{onlFF}_{\mathrm{fa}}$ & $\mathrm{ctOrFF}$ & QFVEr & ON & EQFF \\
\hline$\overline{Q 7}$ & SudgF $\mathrm{F}^{\mathrm{V}}$ & $\overline{\mathrm{ON}}$ & $r$ OMFeC & ofthe 1 & ptorm & $\overline{\mathrm{ON}}$ \\
\hline Q8 & aldiffe & encé & ON & inQ⿻肀一𠃋 c & $\mathrm{BFF}$ & culfFed \\
\hline 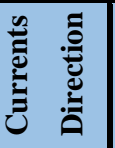 & $+\mathbf{A}$ & $+B$ & $+\mathrm{C}$ & $-\mathbf{A}$ & -B & $-\mathrm{C}$ \\
\hline
\end{tabular}

back-EMF and the supply voltage will be sufficient for the motor to draw the rated current and deliver the rated torque. The stator has three phase windings, and each winding is displaced by 60 degrees. The windings are distributed so as to produce trapezoidal back-EMF. The three phase currents are controlled to take a quasi-square waveform in order to synchronize with the trapezoidal back-EMF to produce the constant torque. [8]

$e=K e * W e$

where $\quad \mathrm{Ke}$ is the back EMF constant

$\mathrm{W}_{\mathrm{e}} \quad$ is the rotor speed

And the instantaneous values of the back- EMF of three phases as follow;

$\theta a=K e * W e * F a(\theta)$

$e b=K e * W e * F b(\theta)$

$\theta c=K e * W e * F c(\theta)$

As shown in Fig. (4) there are six states govern the motor motion by switching the eight electronic switches shown in Fig. (3) and according to table [1]. As each state vary every 60 degrees to supply phases $\mathrm{A}, \mathrm{B}$ and C. According to ESBC topology we can calculate motor back-EMF for phases $\mathrm{A}, \mathrm{B}$ and $\mathrm{C}$ as shown in Fig. (4).

Table [1] Switching Sequence

The back-EMF of phase A (ea) increases linearly from zero to maximum value from $(0<\theta<30)$ then remains constant at its maximum value from $(30<\theta$ $<150)$ and decreases linearly to zero from $(150<\theta<$ $180)$, then this form repeated in the opposite direction as shown in Fig. (5).

Thus the back-EMF is calculated by: -

$\theta a=K e * W e * F a(\theta)$.

where $F a(\theta)$ have the next form

$$
\mathrm{f}(\mathrm{a})= \begin{cases}\left(\frac{6}{\pi}\right) \theta, & \left(0 \leq \theta<\frac{\pi}{6}\right) \\ 1_{x} & \left(\frac{\pi}{6} \leq \theta<\frac{5 \pi}{6}\right) \\ -\left(\frac{6}{\pi}\right) \theta+6, & \left(\frac{5 \pi}{6} \leq \theta<\frac{7 \pi}{6}\right) \\ -1_{x} & \left(\frac{7 \pi}{6} \leq \theta<\frac{11 \pi}{6}\right) \\ \left(\frac{6}{\pi}\right) \theta-12_{v} & \left(\frac{11 \pi}{6} \leq \theta<2 \pi\right)\end{cases}
$$

The back-EMF waveforms of phase B (eb) and phase $\mathrm{C}$ (ec) take the shape of ea but shifted from ea by 60 degrees and 120 degrees respectively as shown in Fig. (5), and they can be calculated as follows: -

$e b=K e * W e * F b(\theta)$.

where $F b(\theta)$ have the next form

$\mathrm{f}(\mathrm{b})= \begin{cases}-1_{s} & \left(0 \leq \theta<\frac{\pi}{6}\right) \\ \left(\frac{6}{\pi}\right) \theta-2, & \left(\frac{\pi}{6} \leq \theta<\frac{\pi}{2}\right) \\ 1, & \left(\frac{\pi}{2} \leq \theta<\frac{7 \pi}{6}\right) \\ -\left(\frac{6}{\pi}\right) \theta+8, & \left(\frac{7 \pi}{6} \leq \theta<\frac{9 \pi}{6}\right) \\ -1, & \left(\frac{9 \pi}{6} \leq \theta<2 \pi\right)\end{cases}$

$\theta c=K e * W e * F c(\theta)$.

where $F c(\theta)$ have the next form

$\mathrm{f}(\mathrm{c})= \begin{cases}-1_{s}, & \left(0 \leq \theta<\frac{\pi}{2}\right) \\ \left(\frac{6}{4}\right) \theta-4, & \left(\frac{\pi}{2} \leq \theta<\frac{5 \pi}{6}\right) \\ 1_{s} & \left(\frac{5 \pi}{6} \leq \theta<\frac{9 \pi}{6}\right) \\ -\left(\frac{6}{\pi}\right) \theta+10, & \left(\frac{9 \pi}{6} \leq \theta<\frac{11 \pi}{6}\right) \\ -1_{s} & \left(\frac{11 \pi}{6} \leq \theta<2 \pi\right)\end{cases}$

Then the motor electromagnetic torque is expressed by:

$$
T e=\frac{(e a * i a+e b * i b+e c * i c)}{w_{r}}
$$




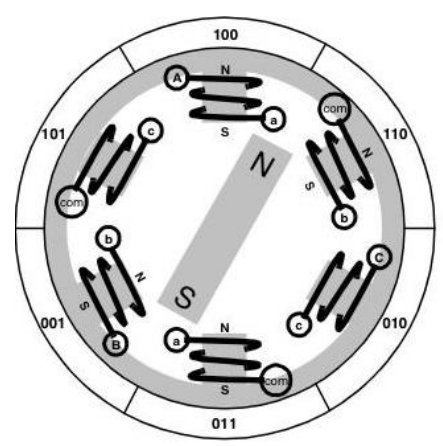

Fig. (4) Brushless DC machine internal diagram

The BLDCM phases currents A,B and C shown in Fig. (6). Each phase shifted from another one by 60 degrees. Phase voltage, back-EMF, phase current of phase A and supply current shown in Fig. (7).

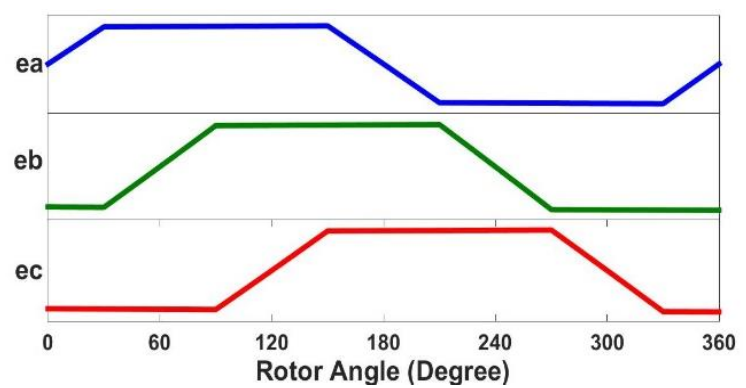

Fig.(5) Back-EMF waveform for ea, eb, and ec

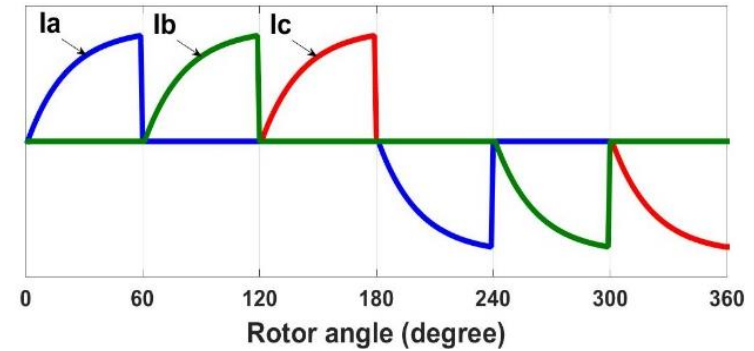

Fig. (6) The motor phases current with Eight Switches Bridge Converter

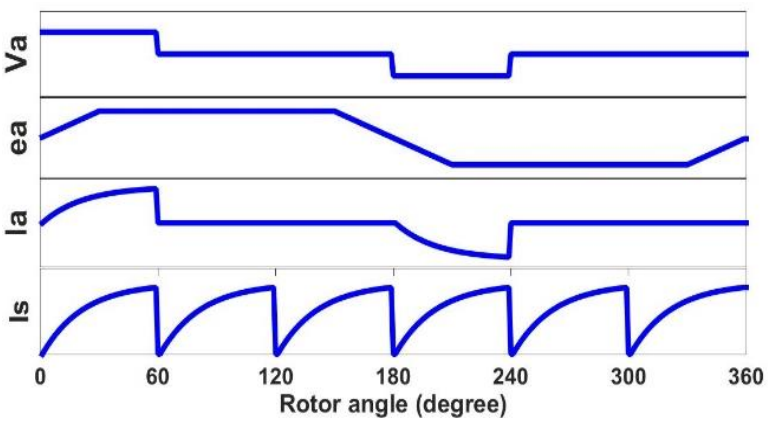

Fig. (7) Voltage source (va), Back-emf (ea), phase current (ia) and Supply current (Is)

\section{SIMULATION RESULTS}

The Eight Switches Bridge Converter (ESBC) is built using MATLAB code (m-file) for a $35 \mathrm{KW}$ Brushless DC Motor parameters as given in
Appendix. A $35 \mathrm{KW}$ BLDCM is designed according to a certain Electric Vehicle (EV) parameters. The performance characteristics of ESBC are tested when disconnecting one phase, switch (Q1), switch (Q2) and two switches (Q1+Q2). First when one phase disconnected the motor current increased by about $20 \%$ compared with the current at normal condition as shown in Fig. (8-a, b) and the motor speed decreased by $18 \%$ compared with the speed at normal condition and ripples featured at speed wave as shown in Fig. (9). When repeating the experiment and disconnect switch (Q1), switch (Q2) and two switches (Q1 + Q2). It is noticed that the supply current increased by $8 \%, 17 \%$ and $25 \%$ respectively as shown in Fig. (8- c, d, e). The motor speed decreased for the three conditions by $4 \%, 12 \%$ and $28 \%$ respectively as shown in Fig. (9).

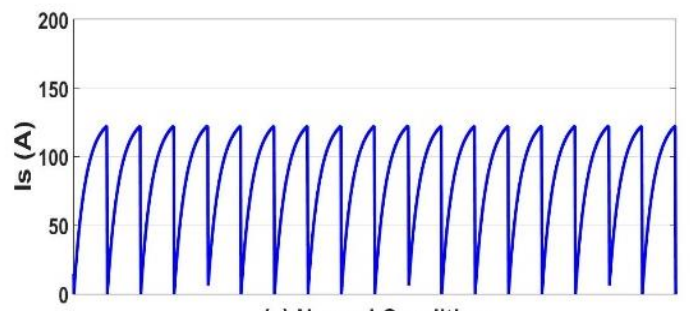

(a) Normal Condition
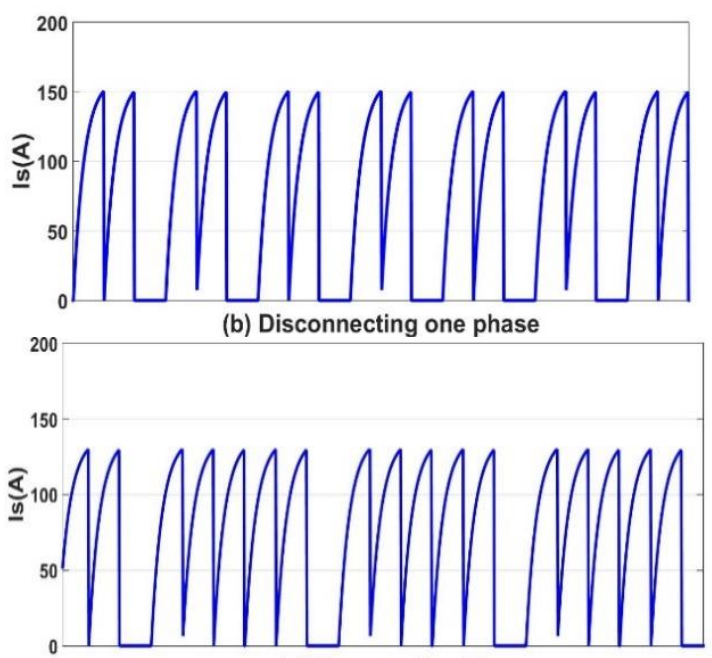

(c) Disconnecting Q1

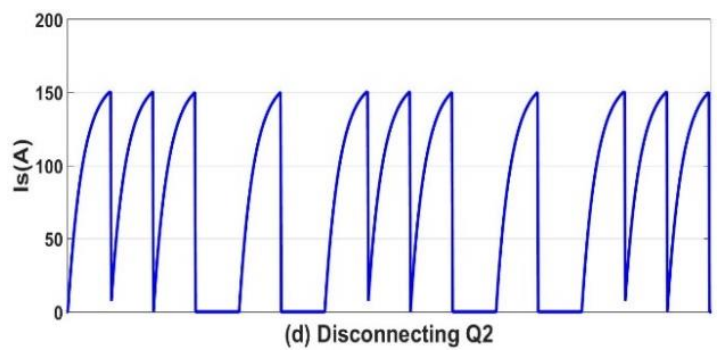




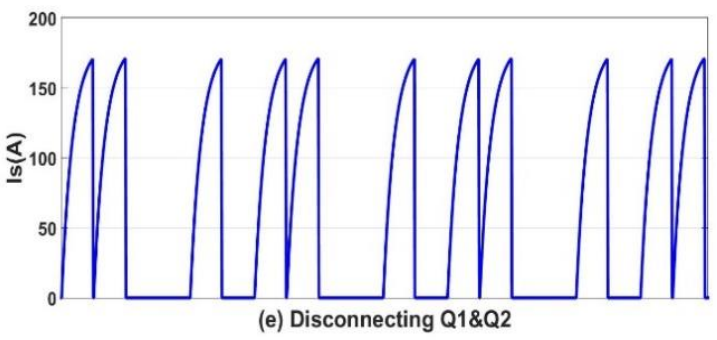

Fig. (8) Supply current at (a) Normal condition, and when disconnecting (b)one phase, (c) Q1, (d) Q2, (e) $(\mathrm{Q} 1+\mathrm{Q} 2)$

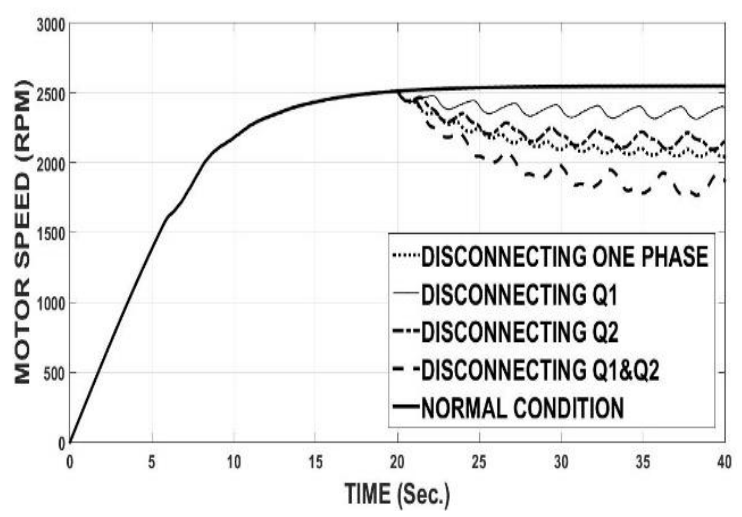

Fig. (9) Motor speed when disconnecting (one phase, Q1, Q2, and Q1\&Q2)

\section{EXPERIMENTAL RESULTS}

For investigative theoretical results, experimental

\begin{tabular}{|c|c|c|c|c|}
\hline \multirow[b]{2}{*}{ Condition } & \multicolumn{2}{|c|}{ Supply current } & \multicolumn{2}{|c|}{ Motor speed (rpm) } \\
\hline & 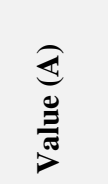 & 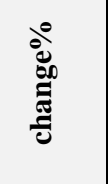 & 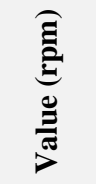 & 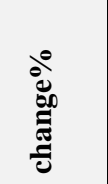 \\
\hline Normal condition & 0.233 & - & 376 & - \\
\hline Disconnect phase & 0.296 & $+21.3 \%$ & 315 & $-16.2 \%$ \\
\hline Disconnect Q1 & 0.27 & $+13.7 \%$ & 355 & $-5.5 \%$ \\
\hline Disconnect Q2 & 0.293 & $+20.4 \%$ & 312 & $-17 \%$ \\
\hline Disconnect $(\mathbf{Q 1 , Q 2})$ & 0.32 & $+27.1 \%$ & 258 & $-31.3 \%$ \\
\hline
\end{tabular}

setup of the BLDCM control system based Eight Switches Bridge Converter (ESBC) established and tested as shown in Fig. (10).

Due to unavailability of $35 \mathrm{KW}$ BLDCM in laboratory, a $0.25 \mathrm{KW}$ BLDCM was built to execute practical experiments as given in Appendix and shown in Fig. (11). Initially, ESBC shown in Fig. (12) feeds the three phases of $\operatorname{BLDCM}(A, B, C)$ separately by using four switches to feed one phase in both directions. In details, phase A connected via switches (Q1, Q6) and (Q2, Q5) in the positive and negative directions respectively. Similarly, phase B connected via switches (Q2, Q7) and (Q3, Q6). Also phase C connected via switches $(\mathrm{Q} 3, \mathrm{Q} 8)$ and $(\mathrm{Q} 4$, Q7) as illustrated in table (1).

ESBC shown in Fig. (12) derived by photo sensors through gate drive circuits and the supply current, phase current and pulses waveforms are shown in Fig. (13). The pulses waveform of upper switches (Q1,Q2,Q3,Q4) and lower switches (Q5,Q6,Q7,Q8) are shown in Fig.(14). The performance characteristics of ESBC with BLDCM are evaluated and tested under different operating conditions.

At normal condition the current value was equal to $0.233 \mathrm{~A}$ and the motor speed was equal to $376 \mathrm{rpm}$ as shown in Fig. (15-a). The rest of the cases were studied at motor rotation. Firstly, when diconneting one phase the current increased by $21.3 \%$ and the motor speed decreased by $16.2 \%$ compared with normal condition results as shown in Fig. (15-b). When repeating the experiment and disconnect switch (Q1), switch (Q2) and two switches (Q1+Q2). It is noticed that the supply current increased by $13.7 \%, 20.4 \%$ and $27.1 \%$ respectively as shown in Fig. (16-c,d,e). The motor speed decreased for the three conditions by $4 \%, 12 \%$ and $28 \%$ respectively as shown in table (2).

The waveforms of the motor currents are measured on a storage oscilloscope type FLUKE 190-104.

FLUKE 175 TRUE RMS MULTIMETER was used to measure the values of the motor currents.

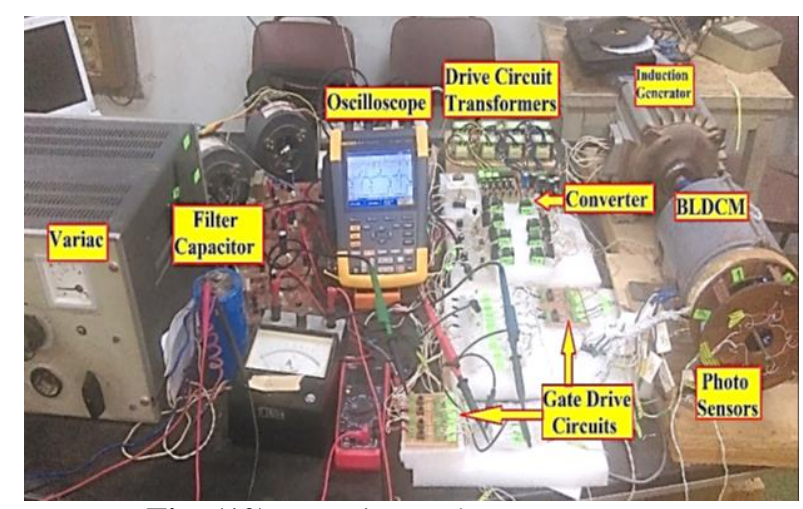

Fig. (10) Experimental system setup

Table (2) Experimental results 


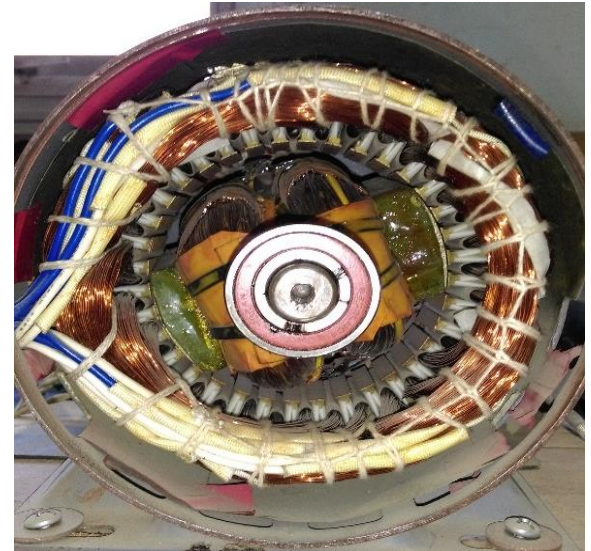

Fig.(11) $0.25 \mathrm{KW}$ Brushless DC motor

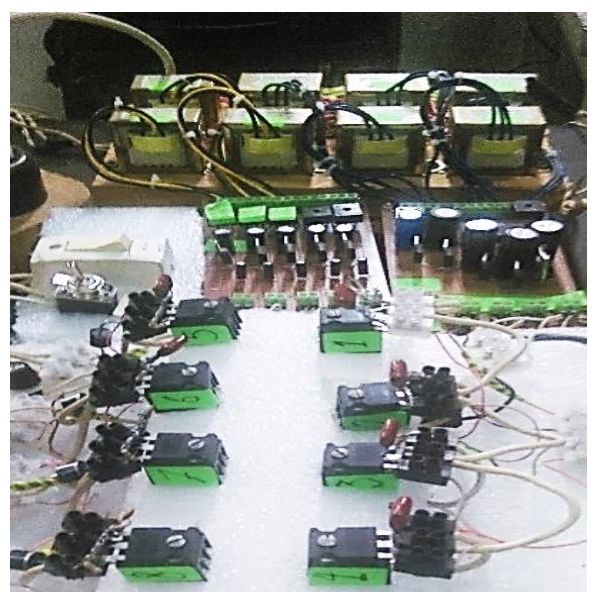

Fig. (12) Eight switches bridge converter (ESBC)

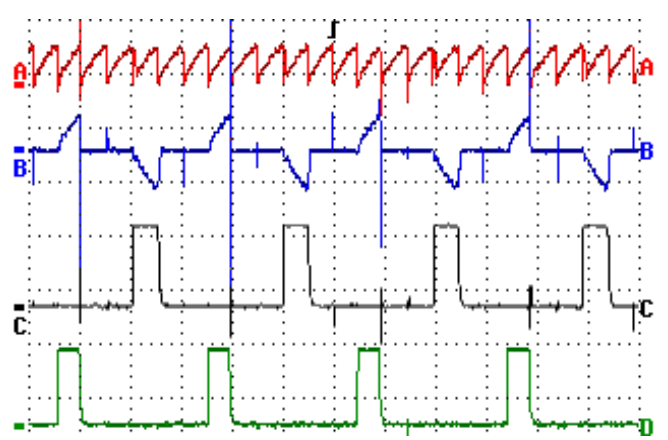

Fig. (13) supply current, phase current and pulses waveforms

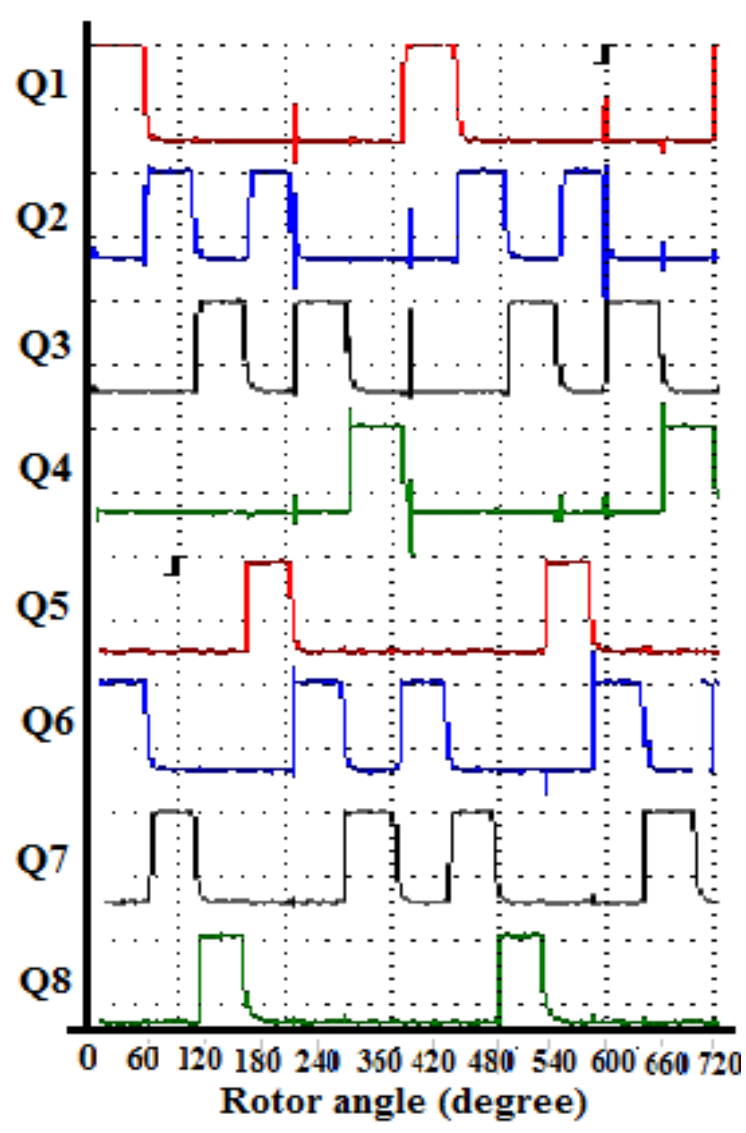

Fig. (14) pulses waveform of eight switches

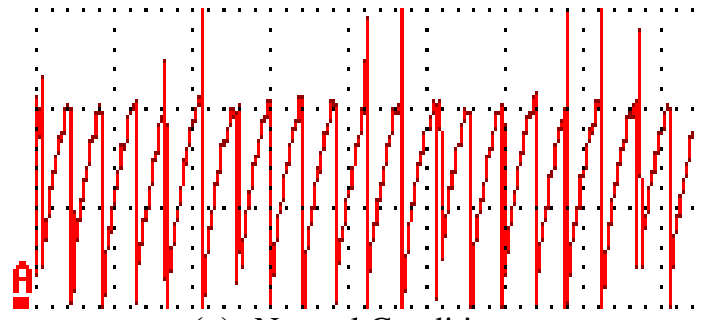

(a) Normal Condition

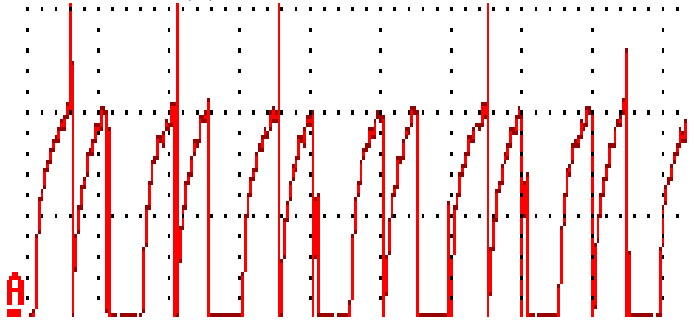

(b) Disconnecting one phase

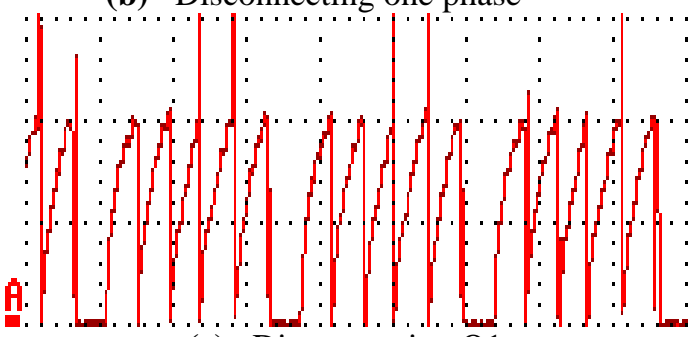

(c) Disconnecting Q1 


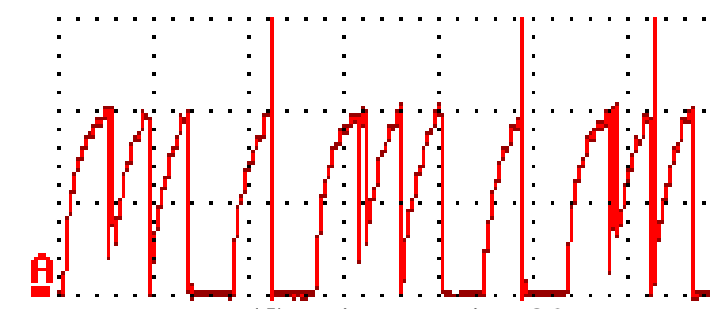

(d) Disconnecting Q2

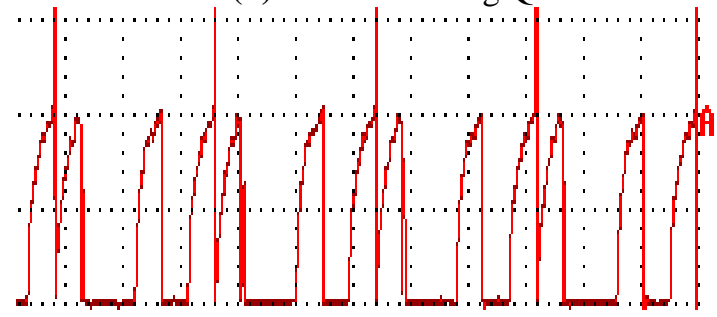

(e) Disconnecting Q1\&Q2

Fig. (15) Experimental supply current at (a) Normal condition, and when disconnecting (b)one phase, (c) $\mathrm{Q} 1,(\mathrm{~d}) \mathrm{Q} 2$, (e) $(\mathrm{Q} 1+\mathrm{Q} 2)$

\section{CONCLUSION}

Eight Switches Bridge Converter has been proposed to drive the Brushless DC motor. The converter is used to increase the reliability of the operating system during faults. The experimental setup is verified the simulation results. The proposed converter achieved electrical separation between motor phases. This is achieved through four conditions of disconnecting phase and different switches. This is to give the EV ability to park or go home. Comparisons validated the feasibility and effectiveness of the proposed converter.

\section{APPENDIX}

Data of $35 \mathrm{kw}$ BLDCM:

Rated power $=35 \mathrm{kw}$, Rated speed $=2500 \mathrm{rpm}$, Number of phases $=3$, No. of poles $=2$, Phase resistance $=0.185 \mathrm{Ohm}$, Phase inductance $=3.2 \mathrm{mH}$, Moment of inertia $=45 \mathrm{e}^{-4} \mathrm{~kg} \cdot \mathrm{m}^{2}$, Damping ratio $=0.28 \mathrm{e}^{-3} \mathrm{NM}$.

Data of $0.25 \mathrm{kw}$ BLDCM:

Rated power $=0.25 \mathrm{kw}$, Rated speed $=2500 \mathrm{rpm}$, Number of phases $=3$, No. of poles $=2$, Phase resistance $=4 \mathrm{Ohm}$, Phase inductance $=0.3 \mathrm{mH}$,

\section{REFERENCES}

[1] Ehsani M., Rahman K.M., Toliyat H.A., "Propulsion System Design of Electric and Hybrid Vehicles ', IEEE Transactions on Industrial Electronics, 1997, 44(1), p. 19-27.

[2] Husain I., 'Electric and Hybrid Vehicles Design Fundamentals ", Taylor \& Francis e-Library, 2005.
[3] A. Tashakori, M. Ektesabi and N. Hosseinzadeh, "Modeling of BLDC Motor with Ideal BackEMF for Automotive Applications ', World Congress on Engineering, ISSN: 2078-0958, 2011, July 6 - 8, London, U.K.

[4] X. Nian, F. Peng and Hang Zhang, "'Regenerative braking system of electric vehicle driven by brushless DC motor ", IEEE Transactions on Industrial Electronics, October 2014, Vol. 61, No. 10.

[5] Sunita P. Kanjhani, Manab Sen Gupta and Harpreet Singh, " Review of different control topologies for the permanent magnet brushless dc motor drives, "International Journal of Advanced Engineering Research and Studies, ISSN: 2249-8974, Oct.-Dec.,2012, Vol. II, Issue I, pp:139-143.

[6] D.Caroline, L.Vincent, F.Guy, " Inverter topology comparison for remedial solution in transistor faulty case ", Laboratoire d'Electromécanique de Compiègne, ISBN : 9789075815108, 2007, pp:1-8.

[7] Mecrow B.C., Jack A.G., Haylock J.A. and Coles J., Fault Tolerant Permanent Magnet Machine Drives, IEE Proceedings Electric Power Application, November 1996, Vol 143, No. 6, pp 437-441

[8] Hemchand Immaneni, ' Mathematical Modelling And Position Control Of Brushless Dc (Bldc) Motor ', International Journal of Engineering Research and Applications (IJERA), ISSN: 2248-9622, May-Jun 2013, Vol. 3, Issue 3, pp.1050-1057.

[9] Chang-liang Xia, " Permanent Magnet Brushless DC Motor Drives and Controls ', 2012.

[10] R. Krishnan, ' Permanent Magnet Synchronous and Brushless DC Motor Drives ", Taylor \& Francis e-Library, 2010.

[11] J. N. Ansari and Sapna, "Speed control of BLDC motor for electric vehicle," International Journal of Engineering Research \& Technology (IJERT), ISSN: 2278-0181, May 2014, Vol. 3, Issue 5. 